tralia, but well remembered from his Cambridge and Edinburgh days) surveyed the problem of domestic cattle in the tropics, especially from the point of selective breeding, and he showed, among other things, how elipping the fur could increase the rate of growth in farm animals, simply by improving heat tolerance. Prof. W. Richards (Bangor) diseussed tropical plants, and he quoted recent evidence from Ibadan and Cambridge that the rapid growth of these plants was related to the favourablo growth of their new leaf. He also quoted some odd rhythrns in equatorial plants, for example, one in singaporo which has a rhythm of 2 years and 8 months, or the Malayan pigeon orchid which flowers quite irregularly though pigeon orchids in any given aroa always flower on the same day.

Prof. C. P. Iuck (Kampala, Uganda) described his studies on elephant, giraffe, rhinoceros and buffalo, which he hunts with cross-bows and suecinyl-cholinimpregnated arrows, so that he can collect sweat, blood and urine, measure body temperatures, or even inoculate animals against diseases, without harm to the animals and, one was glad to hear, with safety to himself. Prof. F. B. Edney (Salisbury, Southern Rhodesia) showed that crabs took increasing amounts of oxygen and survived greater temperatures after acclimatization to heat than before, and that tsetse flies were able to evaporate water from their spiracles, thus avoiding over-heating while engaged in the hard work of sucking bloor in close proximity to a warm animal.

There were many small sessions dealing with more specialized problems. Dr. T. R. A. Davis and Dr. R. J. T. Joy (U.S. Army Research Laboratories, Fort Knox) reported that animals and man exposed to cold for $2 \mathrm{hr}$. daily showed a reduction of shivering after 21-24 days, which was accompanied by an increase of heat production in the muscles without any olectromyographic evidence of shivering. Prof. .). Grayson (Ibadan, Nigeria) produced evidence of similar, apparently purely chemical, heat regulation in the liver, which could also play a part in improved cold tolerance after acclimatization to cold. Related to these findings were those of Prof. H. Hensel and his associates of Marburg, Germany, that cooling of the hypothalamus in animals produced an increase of metabolism in the rest of the body within a few seconds, but more so at lower than at higher environmental temperatures. Taken together, these data probably mean that there may exist a form of true chemical heat regulation not related to shivering, which is probably controlled by the temperature of the hypothalamus, and which can be modified either by thermal impulses from the skin or by a repetition or continuation of the cold stimulus.

Equally interesting was evidence, also from Prol: Hensel, that thermal receptors discharge at a constant level of activity during constant stimulation, so that in the absence of any environmental change the central nervous system receives a constant level of thermal information. In other words, thermal recep. tors would seem to become adapted extremely slowly or not at all. This fits in well with evidence from the Iondon Hospital Medical College that the diminution of sensations and responses to repeated or continued stimuli which plays an important part in acclimatization is a rosult of a central nervous mechanism of habituation and not of any changes in the peripheral receptors.

Other discussions had a wide range, though some did not get beyond defining useful fields for further study. Among these was the problem of air pollution, which appears to be complicated by the fact that certain particles suspended in the air reinforce the action of others. Recognition of one or more potentially harmful substances in the air is therefore insufficient to assess air pollution, and predictions may have to be bassd on a better knowledge of synergistic actions of individual particles.

Difficulties of using scales of environmental comfort were stressed in a very active group on town planning under the chairmanship of Prof. T. K. Page (Sheffield). It appear's that builder's and enginecr's use at least four different comfort scales ; but if one remembers tho effects of habituation on thormal comfort it appears likely that many more comfort, scales would be in use if more people had tried to compute such scales. Evidence was presented also that the provision of warmth is cheaper and easier in cold climates than the provision of eool air in hot places; but this may not always be so, as eivilized communities have studied heating longer than cooling. Evaporating water, where it is available, from the roofs of buildings, as well as the use of solar energy to drive cooling compressors, might lead to simple and cheap ways of avoiding the overheating of buildings or vehicles in hot climates, and considerable improvements may be achieved by good design. Opinions were expressed suggesting that technology may soon romove the need for any physiological adjustments to changes of temperature, but by and large this Congress left the impression that we are still far from the days when uniformly clad people will live at a constant level of thermal acclimatization in one and the same environment anywhere on the Farth and outside it.

F. M. GLaser

\title{
COLONIAL DEVELOPMENT AND WELFARE
}

\footnotetext{
$\mathrm{T}$ HE schemes made under the Colonial Development and Welfare Act in the period April 1, 1959 , to March 31, 1960, which are detailed in the latest return, bring the total commitments, from April 1, 1946, under the Act to $£ 221,023,632$, of which $£ 18,792,837$ is for research schemos*. The totals for the year in question are $£ 33,001,222$ for

* Colonial Development and Welfare Act. Return of Schemes made and of Loans approved under the Colonial Development and Welfare (London: H.M. Stationery Office, 1960.) $2 s$. 6d. net.
}

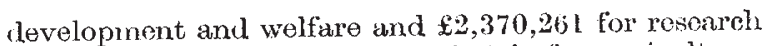

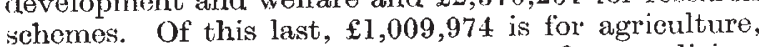

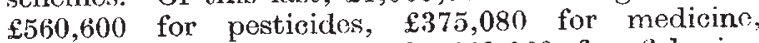
$£ 167,180$ for locust control, $£ 63,860$ for fisheries,

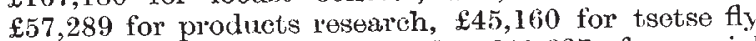
and trypanosomiasis research, $£ 41,697$ for social science, and $\mathfrak{f} 7,796$ for economic research.

Of the actual research schemes, $£ 313,032$ is for the Colonial Pesticides Research Unit, Arusha, Tanganyika, as well as a stpplementary $\mathfrak{f 5 7 , 1 3 9 , 1 9 6 0}$ 
$63 ; £ 181,000$ for the agricultural researoh services, North Borneo, with a further $£ 73,625$ for the establishment of agricultural research stations ; $£ 124,755$ for the Regional Research Centre at the Imperial College of Tropical Agriculture, Trinidad, and $£ 47,459$ for horbicides research at that College; $£ 69,500$ for the Anti-Locust Research Centre and its extra-mural activities, $1960-61$; and $£ 51,009$ for the Colonial Pesticides Research Unit, Porton, 1960-63. $£ 47,892$ went to the East African Agriculture and Forestry Research Organization, $£ 33,504$ to the East African Trypanosomiasis Research Organization, and £33,283 to the East African Veterinary Research Organization; $£ 38,250$ was for trials with anti-typhoid vaceiness ; $£ 55,506$ to the Wellcome Institute for research on foot-and-mouth disease; $£ 57,295$ to the West African Rice Research Station, Rokupr, 1960-61; $£ 77.911$ for improvement and extension of agricultural facilities, Sarawak ; and $£ 33,350$ for the study of dental leishmaniasis, British Honduras.

Other major research schemes include a supplementary $£ 17.174$ to the Fish Culture Researeh Institute, Malacca ; $£ 18,503$ for research on spraying techniques and trace element deficiencies at Long Ashton; $£ 42,968$ for trachoma research in London and in The Gambia; $£ 25,920$ for the Desert Locust. Survey ; $£ 16,607$ for research into farm production costs, Kenya; and $£ 39,650$ for cereals research, Kenya, as well as $£ 21,235$ for research on coffee berry disease there, 1960-62; a supplementary $£ 20,153$ for cotton pest research, Nyasaland; $£ 22,930$ for the Joint Fisheries Development and Research Unit, Sierra Leone, 1960-62; a supplementary $£ 19,489$ for the Colonia! Microbiological Research Institute,
Trinidad; and $£ 15,126$ for the East African Virus Research Institute; $£ 27,882$ was for the Colonial Pesticides Information Service, 1960-64; $£ 16,500$ for Overseas Research Fellowships, 1960-64; and $£ 15,000$ for Colonial Medical Research Studentships, 1960-64.

Development and welfare schemes of scientific interest include $\mathfrak{1 7 , 2 3 2}$ to the Overseas Geological Surveys for age determination of rocks at the Geological Museum, University of Oxford ; $£ 25,930$ for the Desert Locust Survey ; grants totalling $£ 376,633$ to the Agricultural Department, Kenya, for the intensification of African agriculture, 1958-59; a supplementary $£ 74,974$ to Somaliland for scholarships and training abroad; $£ 182,000$ for the establishment of a Nature conservation area in the Ngorongoro Crater Highlands, Tanganyika; $£ 68,500$ for intensified control in Tanganyika of the Sudan dioch (grain. eating birds); and a supplementary £157,685 for forestry development, British Honduras. Educational grants include, besides $£ 250,000$ for a student hostel block, University College, Ibadan, Nigeria, a number of grants totalling more than $£ 169,000$ to the Nigerian College of Arts, Science and Technology ; $£ 210,000$ and $£ 233,250$ for the second and third phase, respect ively, of the expansion of general education in Lagos : $£ 308,120$ for building of schools in Northern Nigeria (with $£ 341,500$ for the development of health services) ; $\$ 368,000$ to Fourah Bay College, Sierra Leone. for constructing and equipping two halls of residence, as well as $£ 360,000$ for the construction and equipment of Freetown Teacher Training College, Sierra Leone, and miscellaneous grants totalling more than $£ 780,000$ to the University College of the West Indies.

\section{CONTROL OF INFECTIONS}

$\mathrm{D}^{\mathrm{L}}$ UE mainly to vaccination, fewer persons now suffer or die from such diseases as diphtheria, poliomyelitis and tuberculosis. If immunization programmes using the best available vaccines were more generally applied, the risk of infection from certain diseases could still further be reduced. Some of the problems raised by vaccination procedures are discussed in a recently published report of a European Technical Conference on the Control of Infectious Diseases through Vaccination Programmes*.

The report gives a broad picture of the legislation in force regarding vaccination in Europe. Compulsory vaccination varies considerably from one country to another; many use a mixed system in which some vaccinations are compulsory while others are not, and the general tendency is to substitute effective health education for compulsion by law. An impor. tant aspect is that of inspection and the recording of vaccinations, which makes it possible to obtain reliable data regarding their effectiveness. Generally the cost of vaccination programmes is borne by the health authorities; in some cases the cost has to be met by the patient himself, which may adversely affect the success of the campaign.

* World Health Organization. Publication No. 198: European Technical Conference on the Control of Infectious Diseases through Vaccination Programmes, Rabat, Morocco, 23-31 October, 1959. Pp. 21. (Geneva: World Health Organization; London : H.M. Stationery
Office, 1960.) 1. Swiss franc; 1s. 9d.; $0: 30$ dollars.
The report gives a brief account of the value and present state of the most important vaccinations. Although smallpox does not exist as an endemic disease in European countries, it was generally felt that it was still necessary to maintain a relatively high level of immunity in the population through continued vaccination programmes. It was agreed that $B C G$ vaccination should be considered as part of the over-all tuberculosis control programme of any country. The report discusses the types of antipolio vaccines used at present; inactivated virus vaccine and attenuated live virus vaccine, which have been successfully applied in the Soviet Union to more than twelve million persons. The use of triple vaccine against diphtheria, tetanus and pertussis is recommended, and consideration is given to thr suitability and effectiveness of many other vaccines, such as those against influenza, typhoid, paratyphoid, tularæmia, brucellosis, rabies, etc, as well as those used against quarantinable diseases (yellow fever. typhus and cholera).

After dealing with the risks and techniques of different vaccinations, the report discusses the importance they may have in the control of infectious diseases. It finally suggests models for programmes which, in the opinion of the conference, might be adopted in the various countries according to the degree of development of their health services and their own particular problems. 